\title{
Investigation of the bottom ash slags influence on the heavy concrete frost resistance
}

\author{
Volodymyr Shulgin, Dmytro Yermolenko, Heorhii Durachenko, Oleksandr Petrash, and \\ Oksana Demchenko* \\ Poltava National Technical Yuri Kondratyuk University, Pershotravnevyi Avenue, 24, Poltava, \\ 36011, Ukraine
}

\begin{abstract}
This paper addresses the issue of the influence of cement consumption, plasticizing additive, and compaction time on the strength and frost resistance of concrete manufactured with bottom ash slags from thermal power plants. The investigation was carried out using the threefactor experiment with variables varied at three levels. There were received response functions, which characterize the correlation between frost resistance and variables: cement consumption, plasticizer additives and compaction time. An analysis of the surface of the response function, where the frost resistance of the concrete was accepted as a response, revealed the optimal correlation between the components of the mixture and the compaction time of the seal. By using the STATISTICA 12 software complex, the values of the factors were specified, when the optimal components ratio with GLENIUM 51 superplasticizer is achieved for the production of concrete with high frost resistance that is greater than F300. The conclusions quantify the results of the investigation.
\end{abstract}

\section{Introduction}

During combustion of solid fuels for the production of heat and electricity at the thermal power plants waste is generated in the form of slag and ashes. Ash and slag are the largescale waste.

One of the ways to safely dispose of such waste is to use it in the construction industry for the manufacture of heavy concrete. The optimum content of ash in heavy concretes is determined by the selection of specific concrete mixtures under the condition that the necessary indicators of their quality are provided. This paper addresses the issue of the influence of cement consumption [1]. Concrete mixtures with ashes have a higher viscosity, better mobility, less water drainage and stratification, which makes such mixtures ideal for use in monolithic concrete. According to the sources [2], replacement of a part of cement by ash, as a rule, leads to lower frost resistance. This is explained, firstly, by an increase in the actual water-cement ratio and the formation of an additional volume of capillary pores. The reduction of frost resistance is also facilitated by the reduction of the entrained air content when the ash is introduced and the presence of ash in organic residues that swell in water and capable of forming compounds that destroy the binder.

\footnotetext{
'Corresponding author: homenko_81@ukr.net
} 
Organic residues are usually contained in a coarse fraction of ash. Grinding of ash leads to the destruction of organic particles and their uniform distribution throughout the material, which positively affects the frost resistance of concrete.

A significant increase of the frost resistance of concrete with ash can be reached by the introduction of surface-active additives of hydrophobic-plasticizing type into concrete. The plasticizing component of such additives reduces the water consumption of the concrete mixture, and hence the volume of capillary pores. [3-6]. The hydrophobic component, in turn, affects the walls of pores and capillaries in concrete and thus prevents the water from entering them. Thereby, after 150 cycles of freezing and thawing of concrete with the replacement of $20 \%$ of cement by ground molded ash, combined with a complex hydrophobic-plasticizing additive, increased strength by $10 \%$ compared with concrete without ash. The use of a hydrophobic-plasticizer additive when replacing $25 \%$ of cement by fine ash allowed to obtain concrete that is not inferior to the frost-resistance of concrete without ash and capable of withstanding up to 200 freezing and thawing cycles [7]. However, the properties of such concrete are still remaining not investigated and the effect of ash slags on the frost resistance of concrete [8].

\section{Investigation results}

\subsection{Materials for concrete with bottom ash slags}

The main purpose of these investigations is to determine the effect of the composition of concrete mixtures with ash slags on the frost resistance of concrete, and the selection of the most optimal concrete with a strength class of C20/25 using bottom ash slags. The planning of the experiment and the results of research on concrete for strength using ash-slag are given in [9].

For this investigation, a mixture of the following materials was chosen: cement CEM I $42.5 \mathrm{~N}$ which is characterized by high early strength, high content of $\mathrm{C}_{3} \mathrm{~S}$ in clinker and low content of $\mathrm{C}_{3} \mathrm{~A}[10]$.

The ash slag (bottom ash) from Starobesheivska TPP; true density is $2.6 \mathrm{~g} / \mathrm{cm}^{3}$; fill density is $1.206 \mathrm{~g} / \mathrm{cm}^{3}$; fineness modulus 1 ; water consumption $24 \%$. Granite gravel of 5$10 \mathrm{~mm}$ fraction is used as a coarse aggregate, voidness of gravel is $47 \%$, fill density is $\rho_{\mathrm{H}}=1350 \mathrm{~kg} / \mathrm{m}^{3}$, true density is $\rho=2.71 \mathrm{~g} / \mathrm{cm}^{3}$. As an additive, a polycarboxylate superplasticizer is used GLENIUM 51.

\subsection{Mathematical planning of experiments}

The research was planned on the basis of using a three-factor experiment in three levels. As variable factors, there were selected: the consumption of cement, the compaction time of the concrete mixture, and the plasticizer additive consumption.

In order to ensure the appropriate level of porosity and taking into account the features of the source materials structure, the water-cement ratio $(\mathrm{W} / \mathrm{C})$ of 0.4 was taken. In the research, control samples were made on quartz sand with strength of $31 \mathrm{~N} / \mathrm{mm}^{2}$.

\subsection{Regression analysis of the concrete frost resistance investigation}

Frost resistance was determined using a "Concrete-Frost" device. After determining all the results were processed on the $\mathrm{PC}$ using the device programs, which allows determination of water absorption by volume of samples and obtain graphs of change in samples volume in time. In accordance with the composition of concrete for a series of samples, certain 
patterns are noticed. Namely, samples that were made with the maximum expands of plasticizer were distinguished by low frost resistance, as well as those containing the least amount of cement. Below is a detailed analysis of these phenomena.

Using STATISTICA software, the coefficients of the regression equation (Table 1) are derived as well as the exact equation (1).

Table 1. Results of calculation of regression coefficients.

\begin{tabular}{|l|c|c|c|c|c|c|}
\hline \multicolumn{1}{|c|}{ Factor } & $\begin{array}{l}\text { Regressn - } \\
\text { Coeff. }\end{array}$ & Std.Err. & $\mathrm{t}(8)$ & $\mathrm{p}$ & $\begin{array}{c}-95, \%- \\
\text { Cnf.Limt }\end{array}$ & $\begin{array}{c}+95, \%- \\
\text { Cnf.Limt }\end{array}$ \\
\hline Mean/Interc. & -7075.50 & 4743.786 & -1.49153 & 0.179449 & -18292.8 & 4141.773 \\
\hline $\begin{array}{l}\text { (1)Cement consumption. } \\
\mathrm{kg}(\mathrm{L})\end{array}$ & 24.25 & 25.697 & 0.94368 & 0.376756 & -36.5 & 85.013 \\
\hline $\begin{array}{l}\text { Cement consumption. } \\
\mathrm{kg}(\mathrm{Q})\end{array}$ & -0.02 & 0.034 & -0.64231 & 0.541128 & -0.1 & 0.058 \\
\hline $\begin{array}{l}\text { (2)Compaction time, } \\
\text { min.(L) }\end{array}$ & 510.41 & 295.180 & 1.72915 & 0.127408 & -187.6 & 1208.399 \\
\hline Compaction time, min.(Q) & -16.92 & 30.228 & -0.55961 & 0.593195 & -88.4 & 54.561 \\
\hline $\begin{array}{l}\text { (3)Plasticizer consumption. } \\
\text { (L) }\end{array}$ & 443.28 & 166.262 & 2.66616 & 0.032178 & 50.1 & 836.431 \\
\hline $\begin{array}{l}\text { Plasticizer consumption. } \\
\text { 1(Q) }\end{array}$ & -15.85 & 7.557 & -2.09794 & 0.074097 & -33.7 & 2.015 \\
\hline 1L by 2L & -0.90 & 0.583 & -1.53633 & 0.168338 & -2.3 & 0.483 \\
\hline 1L by 3L & -0.45 & 0.292 & -1.53633 & 0.168338 & -1.1 & 0.241 \\
\hline 2L by 3L & -9.19 & 8.746 & -1.05042 & 0.328431 & -29.9 & 11.495 \\
\hline
\end{tabular}

$$
y=-7075.5+24.25 x_{1}-0,02 x_{1}^{2}+510.41 x_{2}-16.92 x_{2}^{2}+443.28 x_{3}-15.85 x_{3}^{2}
$$

The diagram of the marginal average dependence of frost resistance on the variation factors was constructed.

The same dependence is noticed in the investigation of the dependence of frost resistance on the cement quantity (Fig. 1): the greater the quantity of cement, the less frost resistance. For the quantity of cement at $350 \mathrm{~kg} / \mathrm{m}^{3}$, sufficient compaction could not be provided. 


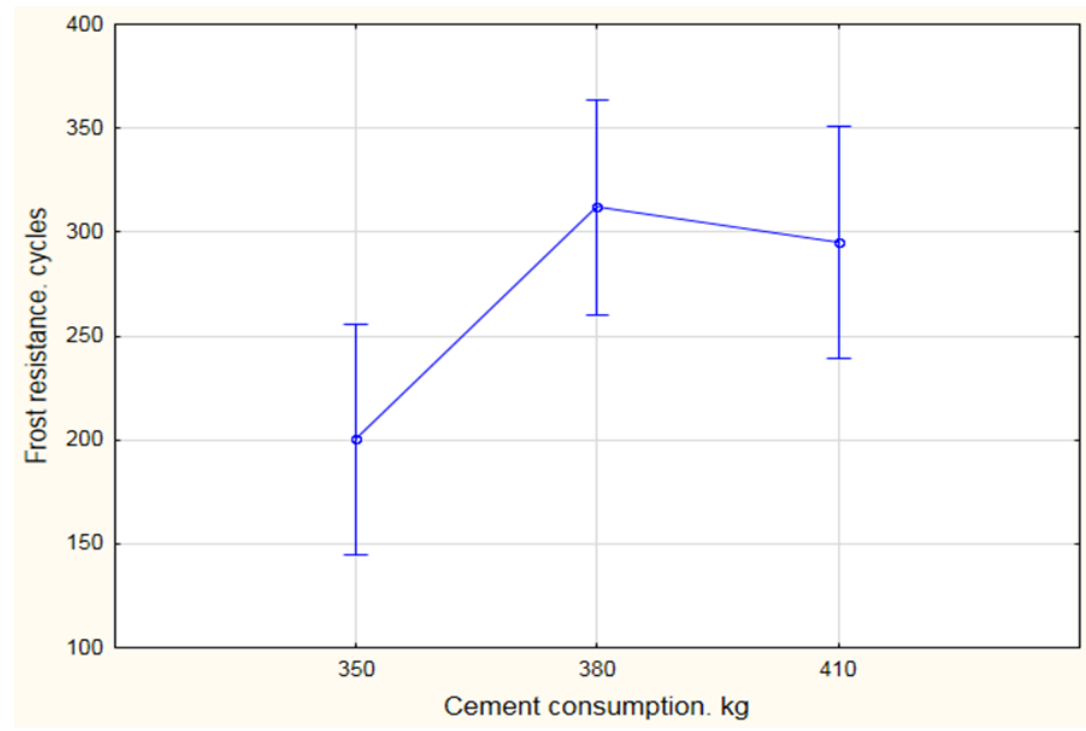

Fig. 1 Diagram of marginal average dependence of frost resistance on cement consumption.

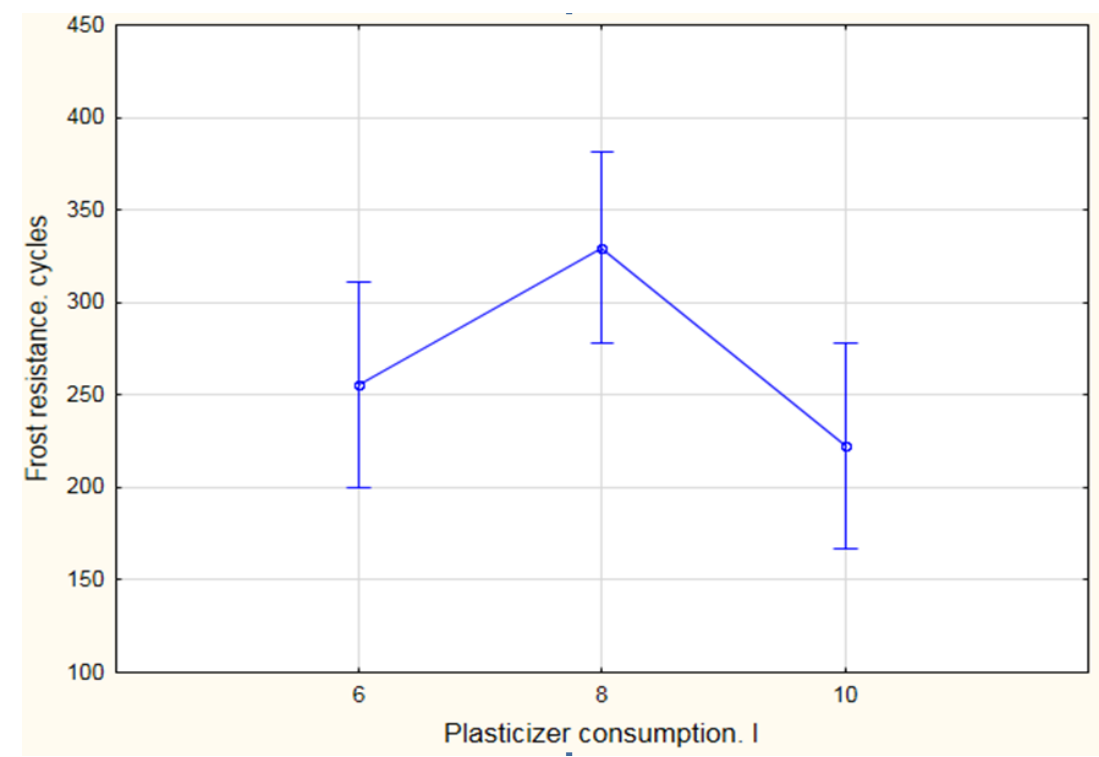

Fig. 2. Diagram of marginal average frost resistance dependence on plasticizer consumption.

The high consumption of plasticizer has an adverse effect on the frost resistance of samples as a chemically active filler (ash-slag) interacts with the organic components of the super-plasticizer additive, the result of which is the emergence of inclusions, which have a negative effect on the frost resistance of the samples.

Low consumption of plasticizer also has a adverse effect on frost resistance, since under such conditions the plasticization action of the supplement is not sufficiently manifested, it is not possible to provide an appropriate level of porosity, resulting in low frost resistance. 


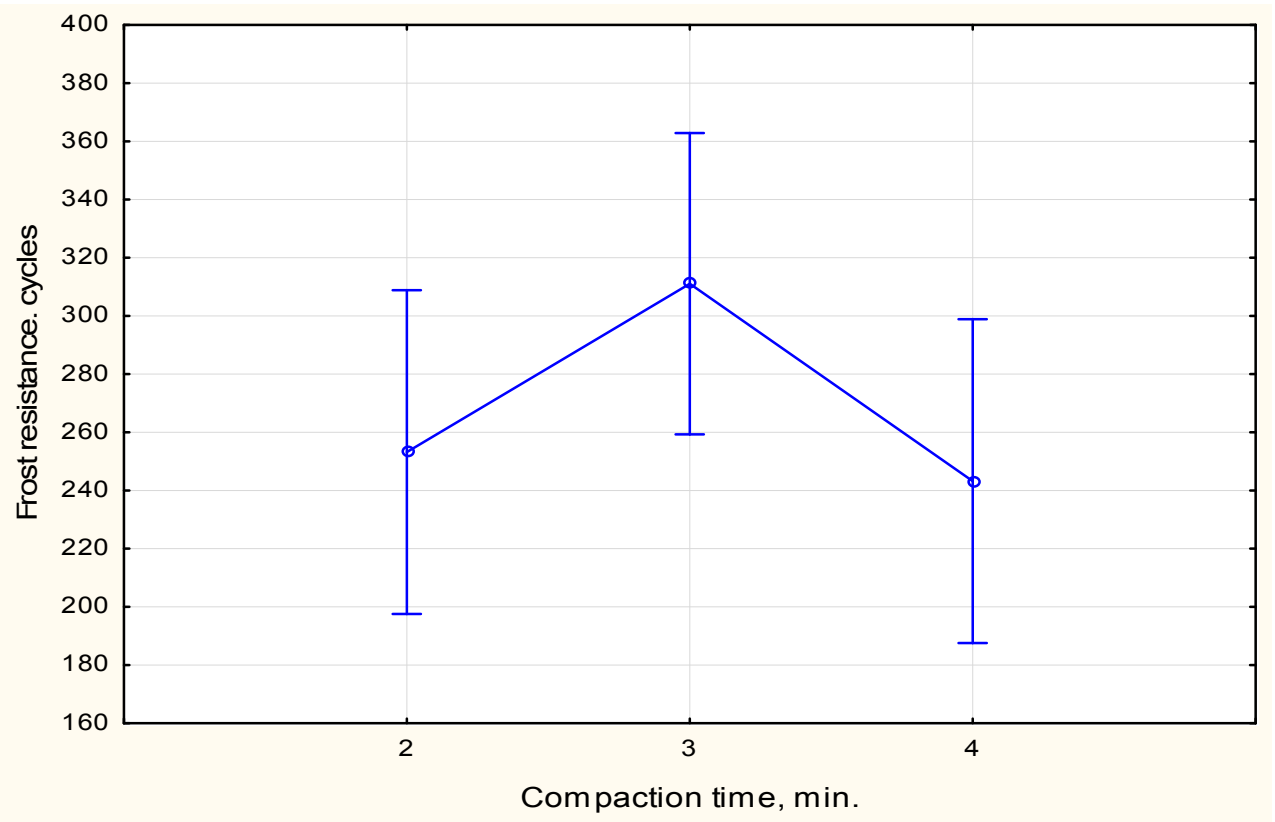

Fig. 3. Diagram of marginal mean frost resistance dependence from compaction time.

As a result of the experiment, it was possible to determine the optimal sample compaction time, which is 3 minutes.

Interconnection of frost resistance and variation factors is obtained. For this purpose, the correlation coefficients have been calculated.

From Table 2 it is getting obvious that plasticizer consumption has the greatest influence on the frost resistance.

Table 2. Results of calculation of correlation coefficients.

\begin{tabular}{|l|c|}
\hline \multicolumn{1}{|c|}{ Factor } & Frost resistance, cycles \\
\hline (1) Cement consumption, $\mathrm{kg}(\mathrm{L})$ & 0.51 \\
\hline Cement consumption, $\mathrm{kg}(\mathrm{Q})$ & 0.43 \\
\hline (2) Plasticizer consumption, \% (L) & -0.18 \\
\hline Plasticizer consumption, \%(Q) & 0.60 \\
\hline (3) Compaction time, $\min (\mathrm{L})$ & -0.05 \\
\hline Compaction time, min (Q) & 0.42 \\
\hline
\end{tabular}

The surfaces of influence are constructed for a clear reflection of the effect of variation factors on the frost resistance using STATISTICA software system. 


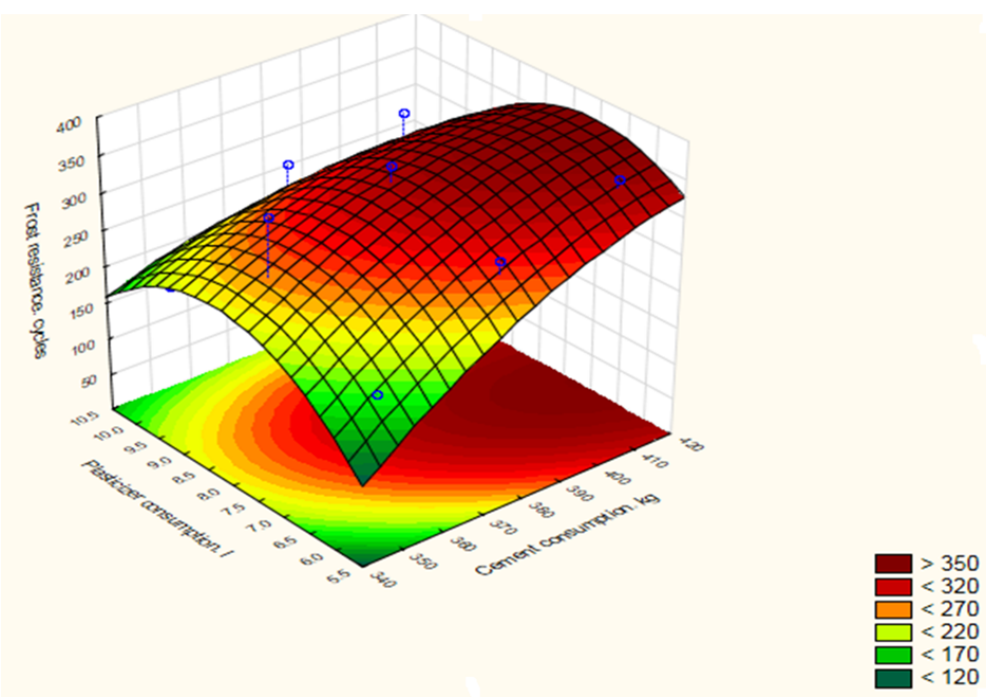

Fig. 4. Surface of the effect of the plasticizer and cement consumptions on frost resistance.

From Fig. 4 it is clear that the highest frost resistance is showed by samples for which the cement consumption is about $400 \mathrm{~kg} / \mathrm{m}^{3}$, and the consumption of plasticiser -8 liters.

Fig. 5 implies that the optimal compaction time is 3 minutes.

Fig. 5 and 6 also suggest that the impact of the compaction time on frost resistance is much less than that of plasticizer and cement.

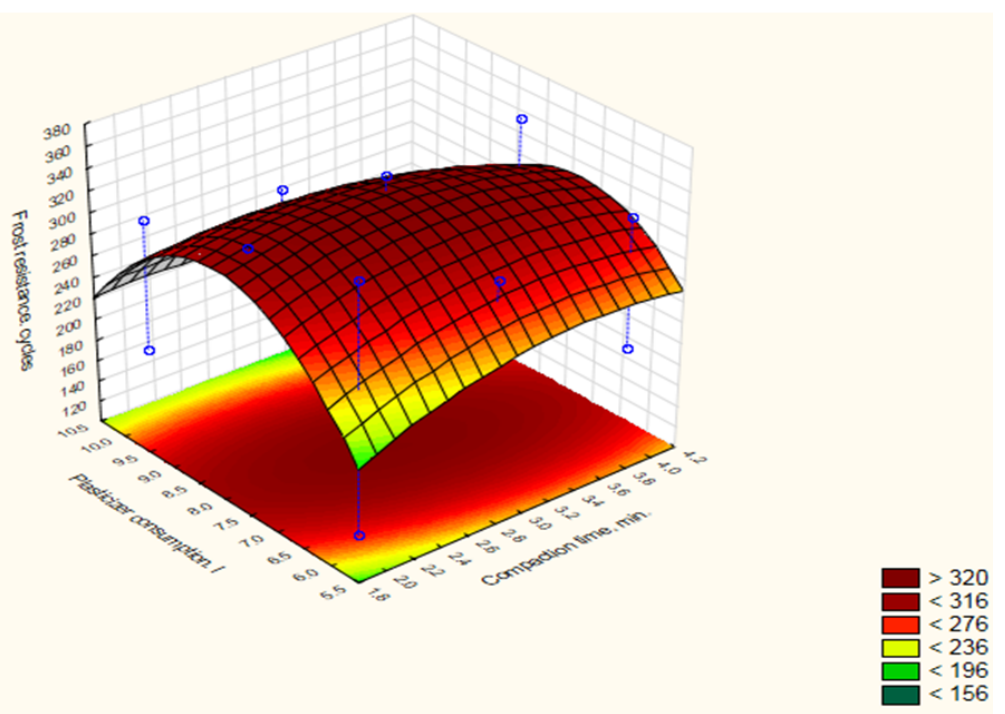

Fig5. The surface of the effect of the plasticizer and the compaction time on frost resistance. 


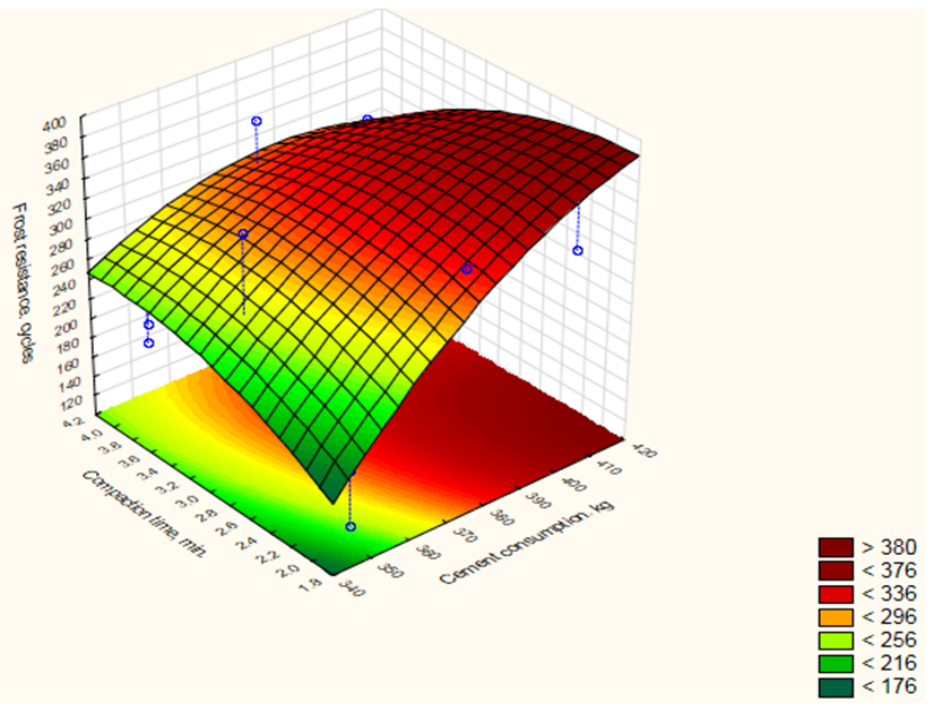

Fig. 6. The surface of the impact of cement consumption and compaction time on frost resistance.

Visual analysis of graphs and surfaces gives only approximate values of optimal component ratios. However, the software complex STATISTICA allows determining the degree of the factors at which the researched values reaches its maximum magnitude (Table 3).

Table 3. Critical variables.

\begin{tabular}{|l|c|c|c|}
\hline \multicolumn{1}{|c|}{ Factor } & Observed - Minimum & Critical - Values & Observed - Maximum \\
\hline Cement consumption, $\mathrm{kg}$ & 350.0000 & 478.0123 & 410.0000 \\
\hline Compaction time, min. & 2.0000 & 2.5065 & 4.0000 \\
\hline Plasticizer consumption. 1 & 6.0000 & 7.0809 & 10.0000 \\
\hline
\end{tabular}

The predicted value of the response (frost resistance) for the above critical values of the input factors is of the order of 377 cycles.

\section{Main conclusions}

Utilizing the bottom ash slag as a fine filler allowed obtaining the concrete of the desired frost resistance class of F300. It should be noted that some samples manufactured using bottom ash-slag had a higher level of frost resistance than ones from the control group. The greatest frost resistance (the average value from the sample series is 317 cycles) was achieved for the cement consumption at $380 \mathrm{~kg} / \mathrm{m}^{3}$. The frost resistance is negatively impacted by the increased $\left(\begin{array}{lll}10 & 1\end{array}\right)$ consumption of plasticizer while the average frost resistance of the samples was 222 cycles. Applying the bottom ash slag as a fine filler allows manufacturing the concrete with a strength of $36 \mathrm{~N} / \mathrm{mm}^{2}$, that corresponds to C 20/25 class of concrete and F 300 frost resistance index. Using the bottom ash slag as a fine filler instead of sand in concrete mixture ensures not only the waste utilization but manufacturing the concrete for road construction as well.

\section{References}

1. Yogesh Aggarwal, Rafat Siddique CONSTR BUILD MATER, 54, 210-223 (2014)

2. Dvorkin L.I. Building Materials from Industrial Waste, (Rostov-on-Don, 2007) 
3. P.V. Krivenko, E.K. Pushkareva, V.I. Gotz, G. Y. Kovalchuk, Tsementy i betony na osnovi palyvnykh zol ta shlakiv (Kiev, 2012)

4. Nurul Izzati Raihan Ramzi Hannan, Shahiron Shahidan, Noorwirdawati Ali, Mohamad Zulkhairi Maarof, MATEC WEB CONF, 97 (2017)

5. V.M. Malhotra, P.K. Mehta, High-Performance, High-Volume Fly Ash Concrete, Inc., (Canada, 2002)

6. N. Zaichenko, A. Serduk, Visnyk DNABiA, 1(99), 137-144 (2013)

7. Seyoon Yoon, P.J.M. Monteiro, D.E. Macphee, F.P. Glasser, Mohammed Salah-Eldin Imbabi, CONSTR BUILD MATER, 54, 432-442 (2014)

8. V.M. Malhotra, High-Performance, High-Volume Fly Ash Concrete, Concrete International 24(7), 30-34 (2002)

9. Victor Bondar, Volodymyr Shulgin, Oksana Demchenko, Ludmila Bondar, MATEC WEB CONF, 116 (2017)

10. P. K. Mehta, High-performance, high-volume fly ash concrete for sustainable Development, International Workshop on Sustainable Development and Concrete Technology, 3-14 (2004) 